
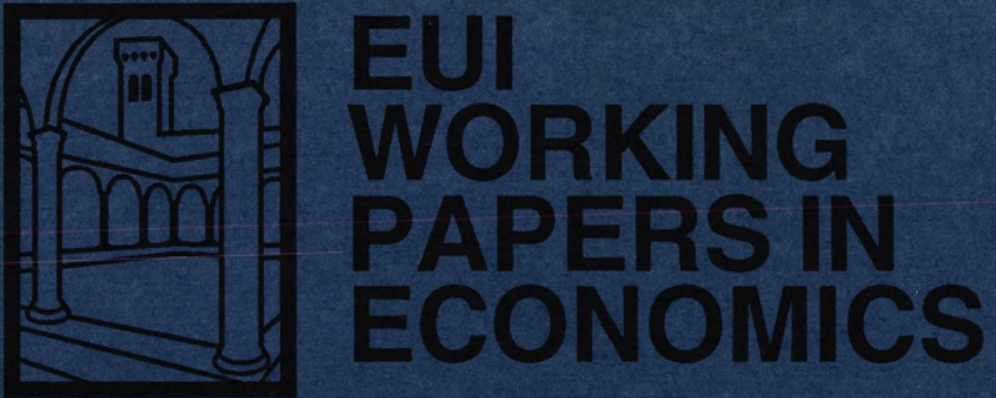

EUI Working Paper ECO No. 94/18

Noise Trading in Small Markets

Frederic Palomino 
European University Library

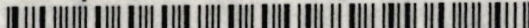

|| ||||||||||||||||||||||||||||||||||||||||||||||||||||||||||||

$3000100158793 \quad 2$ 
EUROPEAN UNIVERSITY INSTITUTE, FLORENCE

ECONOMICS DEPARTMENT

EUI Working Paper ECO No. 94/18

Noise Trading in Small Markets

FREDERIC PALOMINO 
All rights reserved.

No part of this paper may be reproduced in any form without permission of the author.

(C) Frederic Palomino

Printed in Italy in May 1994

European University Institute

Badia Fiesolana

I - 50016 San Domenico (FI)

Italy 


\title{
NOISE TRADING IN SMALL MARKETS
}

\author{
Frederic PALOMINO* \\ European University Institute \\ Florence (Italy)
}

April 29, 1994

\begin{abstract}
Noise traders have often been defined as those who falsely believe that they have private information about the future price of risky assets. Using such a definition, it was demonstrated that, in perfectly competitive markets, when trading against rational investors, noise traders are always expected to disappear in the long run if the imitation rule chosen is based on relative utility levels. In this article, we focus on the survival of noise traders in imperfectly competitive markets. Under such an assumption, we demonstrate that there exist imitation rules based on relative utility levels such that noise traders dominate the market in the long run.
\end{abstract}

*I would like to thank Alan Kirman and Robert Waldmann for helpful comments. The usual disclaimer applies. 


\section{Introduction}

Two ways to model noise trading have been either by way of an exogeneous, inelastic demand for an asset as in Kyle $(1984,1985,1989)$ or in a competitive fashion as in De Long, Shleifer, Summers and Waldmann ${ }^{1}$ $(1989,1990,1991)$. In this last series of articles, noise traders "are those who falsely believe that they have special information about the future price of risky assets". Noise trading results from maximizing behaviour and thus is not infinitely inelastic with respect to prices. However only a perfectly competitive economy is studied. In a model in which traders have an infinite horizon, noise traders may survive in the long run, in the sense that their wealth share in the economy never goes to zero. This happens when their utility is "closer" to the log utility than is the utility of rational investors. Thus, noise traders have a higher expected rate of change of log wealth. Blume and Easley (1989) have generalized this result by demonstrating that

"traders whose expected growth rate of wealth share is posi-
tive, no matter how small, will come to dominate the market
over other traders pursuing strategies that perhaps offer higher
expected returns (measured in either wealth or utility)".

In overlapping generation models, when traders have exponential utility functions and uncertainty is normally distributed, it is established that, in the presence of fundamental risk, noise traders can survive in the long run if the imitation rule chosen is based on realized returns (i.e. noise traders can have higher returns than rational investors). If the imitation rule chosen is based on realized utility levels, noise traders are always expected to disappear in the long run. The reason is that if noise traders are on average bullish, they buy larger quantities of risky asset than rational investors do and thus bear more risk. Noise traders reach a lower utility level because the difference in risk beared offsets the higher return. This analysis should be extended in two directions. First, as in Conlisk (1980), it can be argued that rational investors are not smarter

${ }^{1}$ DSSW henceforth. 
than noise traders but that they spend time analyzing financial reports and processing pieces of information about the asset traded and thus pay a cost for their better knowledge of the market. Therefore, if this cost, which is certain, is larger than the difference in expected utility, noise traders will be expected to survive in the long run. The second extension deals with market size and the intensity of competition between noise traders and rational traders. Speaking about firms, Enke (1951) explains that

"If there is no competition, a great many policies-all "good" but only one "best" - will permit an isolated monopoly to survive, the fact that such a firm exists is not a reason for supposing that it is securing maximum profits. However, if there is intense competition, all policies save the "best" may result in negative profits and in time elimination; then firms that survive must, through some combination of good luck or good management, have happened upon optimal policies."

Our article concentrates on that second issue. We consider an economy in which a finite number of agents trade and behave as imperfect competitors. One can argue that financial markets are usually seen as the best example for a perfectly competitive market. However, as Lakonishok, Shleifer and Vishny (1991) have demonstrated, in small markets, i.e stocks with small market capitalization, institutional investors influence prices. At the scale of the NYSE, it may be of no interest to study small markets, but at the scale of the average size on a European stock exchange, it may become an important issue. Our main result is that, in small markets, noise traders may, on average, dominate the market even with an imitation rule based on utility levels. This result can be easily explained. With imperfect competition, irrational behavior can impose higher costs on rational competitors than on the irrational agent himself [See Schaffer (1989)]. In DSSW's model, imperfect competition increases the difference in returns between noise traders and rational investors and reduces more than proportionately the difference in risk bearing. As noise traders on average dominate the market, it is then of interest to study their impact on the level of social welfare in an imperfectly competitive 
economy. Two issues studied separately in DSSW (1989) and in Pagano (1990) are now mixed. We derive the result that any tax based government policy is Pareto inferior to open market operations aimed out counteracting the effect of noise traders.

The organization of this paper is as follows. In section 2 , the model will be presented. In section 3 , it will be established that there exists an imitation rule based on utility levels,such that noise traders are expected to survive in the long run. In section 4 , the impact of noise traders on the economy will be studied.

\section{The model}

\subsection{Presentation of the model}

We consider a model similar to DSSW (1990), i.e an overlapping generation model with two-period-lived agents where the only decision agents make is to choose a portfolio when young. The economy contains two assets. The first asset $s$ is a risk free bond available in infinitely inelastic supply, so its price is always fixed to one. $s$ pays a fixed coupon $r$. The second asset $u$ is a risky stock. $u$ pays a random dividend $\delta_{t}$ independent and identically normally distributed with mean $\delta^{*}>r$ and variance $\sigma_{\delta}^{2}$. The stock supply is a fixed and unchangeable quantity: $\mathrm{Z}$ units. The price of $u$ in period $t$ is denoted $p_{t}$. There are two types of agents: sophisticated investors (denoted $s$ ) who have rational expectations and noise traders $(\operatorname{denoted} n)$. We assume that $\mathrm{N}$ sophisticated investors and $\mathrm{M}$ noise traders are present in the model and that all agents of a given type are identical. Both types of agents choose their portfolio when young to maximize perceived expected utility given their own beliefs about the ex-ante distribution of $\delta_{t+1}$ and $p_{t+1}$. Both noise traders and sophisticated investors young in period $t$ accurately perceive the distribution of $p_{t+1}{ }^{2}$. The representative sophisticated investor accurately perceives the distribution of $\delta_{t+1}$. The representative noise trader misperceives the ex-

\footnotetext{
${ }^{2}$ In DSSW (1990), noise traders accurately perceive the distribution of the dividend but misperceive the distribution of the price.
} 
pected dividend $\left(\delta^{*}\right)$ by an independent random variable $\rho_{t}$ identically normally distributed with mean $\rho^{*}$ and variance $\sigma_{\rho}^{2}$. Each agent's utility is a constant absolute risk aversion function of wealth when old:

$$
U=-e^{-(\gamma w)}
$$

where $\gamma$ is the coefficient of absolute risk aversion. At time $t(t=$ $1, \ldots, \infty)$, each sophisticated trader $j(j=1, \ldots, N)$ chooses a demand schedule $X_{j, t}($.$) and each noise trader m(m=1, \ldots, M)$ chooses a demand schedule $Y_{m, t}($.$) . Given a market clearing price p_{t}$, the quantities traded by sophisticated and noise traders can be written

$$
x_{j, t}=X_{j, t}\left(p_{t}\right), j=1, \ldots, N ; \quad y_{m, t}=Y_{m, t}\left(p_{t}\right), m=1, \ldots, M .
$$

\subsection{Existence of a Nash equilibrium in demand sched- ules}

Since utility function maximization is equivalent to a quadratic function maximization, we know from Kyle (1989), that if all agents conjecture linear residual supply curve (i.e. for all $j=1, \ldots, N, \tilde{p}_{t}=\tilde{\mu}_{s, i}+\lambda_{s, t} x_{j, t}$ and for all $\left.m=1, \ldots, M, \tilde{p}_{t}=\mu_{n, t}+\lambda_{n, t} y_{m, t}\right)$ then there exists a symmetric linear Nash equilibrium in demand schedules that is also a Rational Expectation Equilibrium. Let $\tilde{R}_{t+1}=\tilde{\delta}_{t+1}+\tilde{p}_{t+1}$. Demand schedules are such that:

$$
\text { If } \begin{aligned}
& 2 \lambda_{s, t}+\gamma \operatorname{Var}_{t}\left(\tilde{R}_{t+1}\right)>0 \\
& X_{j, t}(p)=\frac{E_{s, t}\left(\tilde{R}_{t+1}\right)-p_{t}(1+r)}{\lambda_{s, t}(1+r)+\gamma \operatorname{Var}\left(\tilde{R}_{t+1}\right)}
\end{aligned}
$$

If $2 \lambda_{s, t}+\gamma \operatorname{Var}_{t}\left(\tilde{R}_{t+1}\right)=0$, then

$$
X_{j, t}(p)=\frac{2\left[p_{t}(1+r)-E_{s, t}\left(\tilde{R}_{t+1}\right)\right]}{\gamma \operatorname{Var}_{t}\left(\tilde{R}_{t+1}\right)}
$$

If $2 \lambda_{n, t}+\gamma \operatorname{Var}_{t}\left(\tilde{R}_{t+1}\right)>0$

$$
Y_{m, t}(p)=\frac{E_{n, t}\left(\tilde{R}_{t+1}\right)-p_{t}(1+r)}{\lambda_{n, t}(1+r)+\gamma \operatorname{Var}\left(\tilde{R}_{t+1}\right)}
$$


If $2 \lambda_{n, t}+\gamma \operatorname{Var}_{t}\left(\tilde{R}_{t+1}\right)=0$, then

$$
Y_{m, t}(p)=\frac{2\left[p_{t}(1+r)-E_{s, t}\left(\tilde{R}_{t+1}\right)\right]}{\gamma \operatorname{Var}_{t}\left(\tilde{R}_{t+1}\right)}
$$

where $E_{s, t}$ and $E_{n, t}$ respectively denote the expectation operator at time $\mathrm{t}$ of sophisticated investors and noise traders.

Proposition 1: Assume $I>2$. There exists a symmetric linear Nash equilibrium in demand schedule such that (for all $j=1, \ldots, N$ and for all $m=1, \ldots, M$ )

$$
\begin{aligned}
X_{j, t} & =\frac{(I-2)}{(I-1)} \frac{\left[E_{s, t}\left(\tilde{R}_{t+1}\right)-p_{t}(1+r)\right]}{\gamma \operatorname{Var}_{t}\left(\tilde{R}_{t+1}\right)} \\
Y_{m, t} & =\frac{(I-2)}{(I-1)} \frac{\left[E_{n, t}\left(\tilde{R}_{t+1}\right)-p_{t}(1+r)\right]}{\gamma \operatorname{Var}_{t}\left(\tilde{R}_{t+1}\right)}
\end{aligned}
$$

Remark: This equilibrium may not be unique. However it is the only one such that both sophisticated investors and noise traders consider the risky asset as a normal good. Furthermore, as the only random variable in $\tilde{\mu}_{s, t}$ is $\tilde{\rho}_{t}$, it follows that rational investors have a perfect knowledge of noise traders' beliefs when they compute their demand schedule.

Proof: Assume that for all $j=1, \ldots, N$ and for all $m=1, \ldots, M$,

$$
2 \lambda_{s, t}+\gamma \operatorname{Var}_{t}\left(\tilde{R}_{t+1}\right)>0 \quad 2 \lambda_{n, t}+\gamma \operatorname{Var}_{t}\left(\tilde{R}_{t+1}\right)>0
$$

Then, for all $j=1, \ldots, N$

$$
\begin{aligned}
Z & =(N-1)\left[\frac{E_{s, t}\left(\tilde{R}_{t+1}\right)-p_{t}(1+r)}{\lambda_{s, t}(1+r)+\gamma \operatorname{Var}\left(\tilde{R}_{t+1}\right)}\right] \\
& +M\left[\frac{E_{n, t}\left(\tilde{R}_{t+1}\right)-p_{t}(1+r)}{\lambda_{s, t}(1+r)+\gamma \operatorname{Var}\left(\tilde{R}_{t+1}\right)}\right]+X_{j, t}
\end{aligned}
$$


and, for all $m=1, \ldots, M$

$$
\begin{array}{r}
Z=N\left[\frac{E_{s, t}\left(\tilde{R}_{t+1}\right)-p_{t}(1+r)}{\lambda_{s, t}(1+r)+\gamma \operatorname{Var}\left(\tilde{R}_{t+1}\right)}\right] \\
+(M-1)\left[\frac{E_{n, t}\left(\tilde{R}_{t+1}\right)-p_{t}(1+r)}{\lambda_{s, t}(1+r)+\gamma \operatorname{Var}\left(\tilde{R}_{t+1}\right)}\right]+Y_{m, t}
\end{array}
$$

So, have to solve the following system of equation:

$$
\begin{aligned}
{\left[(1+r) \lambda_{s, t}\right]^{-1}=} & \frac{(N-1)}{(1+r) \lambda_{s, t}+\gamma \operatorname{Var}_{t}\left(\tilde{R}_{t+1}\right)} \\
& +\frac{M}{(1+r) \lambda_{n, t}+\gamma \operatorname{Var}_{t}\left(\tilde{R}_{t+1}\right)} \\
{\left[(1+r) \lambda_{n, t}\right]^{-1}=} & \frac{N}{(1+r) \lambda_{s, t}+\gamma \operatorname{Var}_{t}\left(\tilde{R}_{t+1}\right)} \\
& +\frac{(M-1)}{(1+r) \lambda_{n, t}+\gamma \operatorname{Var}_{t}\left(\tilde{R}_{t+1}\right)}
\end{aligned}
$$

Equations (12) and (13) imply that

$$
\begin{array}{r}
\frac{1}{(1+r) \lambda_{n, t}}+\frac{1}{(1+r) \lambda_{n, t}+\gamma \operatorname{Var}_{t}\left(\tilde{R}_{t+1}\right)}= \\
\frac{1}{(1+r) \lambda_{s, t}}+\frac{1}{(1+r) \lambda_{s, t}+\gamma \operatorname{Var}_{t}\left(\tilde{R}_{t+1}\right)}
\end{array}
$$

It follows that

$$
\lambda_{s, t}=\lambda_{n, t}
$$

Putting (15) in (12) yields

$$
\lambda_{s, t}=\lambda_{n, t}=\frac{\gamma \operatorname{Var}_{t}\left(\tilde{R}_{t+1}\right)}{(N-2)(1+r)}
$$

Q.E.D.

We can see that the demands of imperfect competition are demands of perfect competition weighted by a coefficient of market size. The smaller the market the larger the difference between the demands of perfect competition and the demands of imperfect competition. 


\subsection{The pricing function}

From the demand functions, we can compute the equilibrium price:

$$
\begin{array}{r}
p_{t}=\frac{1}{(1+r)}\left[\frac{N}{I} E_{s, t}\left(\tilde{R}_{t+1}\right)+\frac{M}{I} E_{n, t}\left(\tilde{R}_{t+1}\right)\right] \\
-\frac{Z}{I} \frac{(I-1)}{(I-2)} \frac{\gamma \operatorname{Var}_{t}\left(\tilde{R}_{t+1}\right)}{(1+r)}
\end{array}
$$

We can see that $p_{t+1}$ is independent of $\delta_{t+1}$, therefore

$$
\operatorname{Var}_{t}\left(\tilde{R}_{t+1}\right)=\operatorname{Var}_{t}\left(\tilde{\delta}_{t+1}\right)+\operatorname{Var}_{t}\left(\tilde{p}_{t+1}\right)
$$

It follows that

$$
\begin{gathered}
p_{t}=\frac{1}{(1+r)}\left[\delta^{*}+E_{t}\left(\tilde{p}_{t+1}\right)+\frac{M}{I} \rho_{t}\right] \\
-\frac{Z}{I} \frac{(I-1)}{(I-2)} f r a c \gamma\left[\sigma_{\delta}^{2}+\operatorname{Var}_{t}\left(\tilde{p}_{t+1}\right)\right](1+r)
\end{gathered}
$$

As DSSW(1990), we consider only steady state equilibria by requiring that the unconditional distribution of $\tilde{p}_{t+1}$ is equal to the unconditional distribution of $\tilde{p}_{t}$. Then, we obtain

$$
\begin{aligned}
p_{t}=\frac{\delta^{*}}{r} & +\frac{1}{(1+r)} \frac{M}{I}\left(\rho_{t}-\rho^{*}\right)+\frac{1}{r} \frac{M}{I} \rho^{*} \\
& -\frac{Z}{I} \frac{(I-1)}{(I-2)} \frac{\gamma}{r}\left[\sigma_{\delta}^{2}+\operatorname{Var}_{t}\left(\tilde{p}_{t+1}\right)\right]
\end{aligned}
$$

It follows that

$$
\operatorname{Var}\left(\tilde{p}_{t+1}\right)=\operatorname{Var}_{t}\left(\tilde{p}_{t+1}\right)=\frac{\sigma_{\rho}^{2}}{(1+r)^{2}} \frac{M^{2}}{I^{2}}
$$

Surprisingly, market volatility does not shrink when the degree of competitiveness increases (i.e. when I increases). However equation (21) highlights another effect: variance generated by noise trading. As Pagano (1989) explains

In the real world, even in very deep markets, stock price can be very volatile. This is because in actual markets the variance of stock prices derives from two main factors, i.e the flow 
of new information that at any given moment leads investors to revise their expectation of future dividends and the transaction related noise deriving from the sample variance of investors'demand.

However, although stock price volatility is independent of the degree of competitiveness, looking at equation (20) we can see that the market pays a premium for the lack of competitiveness and this premium decreases when market size increases.

We can now compute the equilibrium price:

$$
\begin{aligned}
p_{t}=\frac{\delta^{*}}{r} & +\frac{1}{(1+r)} \frac{M}{I}\left(\rho_{t}-\rho^{*}\right)+\frac{1}{r} \frac{M}{I} \rho^{*} \\
- & \frac{Z}{I} \frac{(I-1)}{(I-2)} \frac{\gamma}{r}\left[\sigma_{\delta}^{2}+\frac{M^{2}}{I^{2}} \frac{\sigma_{\rho}^{2}}{(1+r)^{2}}\right]
\end{aligned}
$$

Market liquidity does not refer only to market size but instead refers to several properties. Kyle (1985), following Black (1971), reviewed the properties of a liquid market:

"Market liquidity" is a slippery and elusive concept, in part because it encompasses a number of transactional properties of markets. These include "tightness" (the cost of turning around a position over a short period of time), "depth" (the size of an order flow innovation required to change price a given amount), and "resiliency" (the speed with which prices recover from a random, uninformative shock).

Thus the price function tells us that the stock market we consider is very resilient since for all $t, p_{t+1}$ is independent of $\rho_{t}$, and that the lower the share of noise traders in the economy, the deeper the market. As the "tightness" property is irrelevant in this model, we can say that market size does not affect market liquidity but that the share of noise traders in the economy does. 


\subsection{Relative utility of noise traders and sophisti- cated investors}

From the quantities traded and the equilibrium price, we can compute the difference of return between the two categories of agents.

$$
\Delta R E T_{n-s, t}=\left(Y_{t}-X_{t}\right)\left[\delta_{t+1}+p_{t+1}-(1+r) p_{t}\right]
$$

From (8), it follows that

$$
Y_{t}-X_{t}=\frac{(I-2)}{(I-1)} \frac{\rho_{t}}{\gamma\left[\sigma_{\delta}^{2}+\frac{M^{2}}{I^{2}} \frac{\sigma_{\rho}^{2}}{(1+r)^{2}}\right]}
$$

So

$$
E_{t}\left(\Delta R E T_{n-s}\right)=\frac{Z}{I} \rho_{t}-\frac{(I-2)}{(I-1)} \frac{M}{I} \frac{\rho_{t}^{2}}{\gamma\left[\sigma_{\delta}^{2}+\frac{M^{2}}{I^{2}} \frac{\sigma_{\rho}^{2}}{(1+r)^{2}}\right]}
$$

and

$$
E\left(\Delta R E T_{n-s}\right)=\frac{Z}{I} \rho^{*}-\frac{(I-2)}{(I-1)} \frac{M}{I} \frac{\left(\sigma_{\rho}^{2}+\rho^{* 2}\right)}{\gamma\left[\sigma_{\delta}^{2}+\frac{M^{2}}{I^{2}} \frac{\sigma_{\rho}^{2}}{(1+r)^{2}}\right]}
$$

Imperfect competition increases the expected difference of returns between noise traders and sophisticated investors. The reason is that strategic behaviour reduces rational investors incentives to bet against noise traders. Therefore, the difference of utility levels is:

$$
\Delta U_{n-s}=\Delta R E T_{n-s}-\frac{\gamma}{2}\left(Y_{t}^{2}-X_{t}^{2}\right) \operatorname{Var}\left(R_{t+1}\right)
$$

Thus

$$
E_{t}\left(\Delta U_{n-s}\right)=E_{t}\left[\Delta R E T_{n-s}\right]-\frac{\gamma}{2}\left(Y_{t}^{2}-X_{t}^{2}\right) \operatorname{Var}\left(R_{t+1}\right)
$$

given that $Y_{t}^{2}-X_{t}^{2}=\left(Y_{t}-X_{t}\right)\left(Y_{t}+X_{t}\right)$, and using equation (24), It follows that

$$
E_{t}\left(\Delta U_{n-s}\right)=\frac{Z}{I} \frac{\rho_{t}}{(I-1)}-\frac{(I-2)}{(I-1)^{2}} \frac{\left[\frac{(I-2)}{2}+\frac{M}{I}\right]}{\gamma\left[\sigma_{\delta}^{2}+\frac{M^{2}}{I^{2}} \frac{\sigma_{\rho}^{2}}{(1+r)^{2}}\right]} \rho_{t}^{2}
$$


and that

$$
E\left(\Delta U_{n-s}\right)=\frac{Z}{I} \frac{\rho^{*}}{(I-1)}-\frac{(I-2)}{(I-1)^{2}} \frac{\left[\frac{(I-2)}{2}+\frac{M}{I}\right]}{\gamma\left[\sigma_{\delta}^{2}+\frac{M^{2}}{I^{2}} \frac{\sigma_{\rho}^{2}}{(1+r)^{2}}\right]}\left(\rho^{* 2}+\sigma_{\rho}^{2}\right)
$$

Difference of expected utility is increased for two reasons when compared to perfect competition. First, as we have seen above, because the difference of expected returns is increased. Second, because imperfect competition decreases quantities traded and so decreases the difference of risk borne by noise traders and by sophisticated investors ${ }^{3}$. But the main point is that in imperfect competition, for some sets of parameters, noise traders, if they are on average bullish, may expect to reach higher utility levels than sophisticated investors $\mathrm{do}^{4}$. This was not the case in a perfectly competitive economy since the first term in (30) is equal to zero. This term captures the market power of traders.

\section{Imitation of beliefs}

As we consider a model with an integer number of traders, we cannot apply the imitation rule used in DSSW (1990). The one chosen is in the spirit of Kirman (1993).

$$
\begin{array}{rlll}
M_{t-1} \in\{1, \ldots, I-1\} & \text { If } \Delta U_{n-s, t-1}>0 & M_{t+1}=M_{t}+1 \\
& \text { If } \Delta U_{n-s, t-1}<0 & M_{t+1}=M_{t}-1 \\
M_{t-1}=0 & \text { If } M_{t}=0 & \operatorname{Prob}\left(M_{t+1}=1\right)=\alpha \\
& & \operatorname{Prob}\left(M_{t+1}=0\right)=1-\alpha \\
& & \text { If } M_{t}=1 & M_{t+1}=1 \\
M_{t-1}=I & \text { If } M_{t}=I & \operatorname{Prob}\left(M_{t+1}=I-1\right)=\alpha \\
& & \operatorname{Prob}\left(M_{t+1}=I\right)=1-\alpha
\end{array}
$$




$$
\text { If } M_{t}=I-1 \quad M_{t+1}=I-1
$$

where $\left(\Delta U_{n-s, t-1}\right)$ is the difference in relative utility levels between traders young in period $t$. It means that $M_{t+1}$ is determined before $p_{t+1}$ is observed. The specific cases $M_{t-1}=0$ and $M_{t-1}=I$ are necessary conditions to avoid the process to get stuck at 0 or $I$. However the larger $I$, the smaller $\alpha$ can be chosen ${ }^{5}$. The case $M_{t-1}=0$ and $M_{t}=1\left(M_{t-1}=\right.$ $I$ and $\left.M_{t}=I-1\right)$ mean that if imitation is impossible because only sophisticated investors (noise traders) were participating in the market at time $t-1$, but both categories of speculators participate in the market at time $t$, then no imitation occurs and $M_{t+1}=M_{t}$.

Given such an imitation rule, success breeds imitation. However, whatever the extent of the success, the imitation will be constant ${ }^{6}$.

We also assume that traders are bounded rational in the sense that they do not take account of their impact on the number of noise traders of the following generation. They act as if the only risk in the economy were the fundamental risk and noise traders' misperception of the dividend distributed. Given such an assumption,

$$
\begin{aligned}
p_{t}=\frac{\delta^{*}}{r} & +\frac{1}{(1+r)} \frac{M_{t}}{I}\left(\rho_{t}-\rho^{*}\right)+\frac{1}{r} \frac{M_{t}}{I} \rho^{*} \\
& -\frac{Z}{I} \frac{(I-1)}{(I-2)} \frac{\gamma}{r}\left[\sigma_{\delta}^{2}+\frac{M_{t}^{2}}{I^{2}} \frac{\sigma_{\rho}^{2}}{(1+r)^{2}}\right]
\end{aligned}
$$

It follows that for $M_{t}$ and $M_{t+1}$ given

$$
\begin{array}{r}
\Delta U_{n-s, t}=\frac{I-2}{I-1} \frac{\rho_{t}}{\gamma \operatorname{Var}_{t}\left(R_{t+1}\right)}\left(\frac{M_{t+1}}{I} \frac{\left(\rho_{t+1}-\rho^{*}\right)}{1+r}+\delta_{t+1}-\delta^{*}\right) \\
+E_{t}\left(\Delta U_{n-s, t}\right)
\end{array}
$$

where

$$
E_{t}\left(\Delta U_{n-s, t}\right)=\left(\frac{Z}{r I} \frac{(1+r) \operatorname{Var}_{t}\left(R_{t+1}\right)-\operatorname{Var}_{t+1}\left(R_{t+2}\right)}{\operatorname{Var}_{t}\left(R_{t+1}\right)}\right) \rho_{t}
$$

${ }^{5}$ See Kirman (1993)

${ }^{6}$ The imitation rule used in DSSW (1990) is such that, the larger the success, the larger the imitation 


$$
\begin{array}{r}
+\frac{(I-2)}{(I-1)}\left(\frac{\rho^{*}}{r} \frac{\frac{M_{t+1}}{I}-\frac{M_{t}}{I}}{\gamma \operatorname{Var}_{t}\left(R_{t+1}\right)}-\frac{Z}{I}\right) \rho_{t} \\
-\frac{(I-2)}{(I-1)^{2}} \frac{\left[\frac{(I-2)}{2}+\frac{M_{t}}{I}\right]}{\gamma \operatorname{Var}_{t}\left(R_{t+1}\right)} \rho_{t}^{2}
\end{array}
$$

We are interested in the equilibrium distribution of $M_{t}$. Let $\nu$ be this distribution. The complexity of $\Delta U\left(M_{t-1}, M_{t}\right)$ makes it difficult to compute explicitly this distribution. However, some properties can be dirived. Given our imitation rule, $\left|M_{t}-M_{t-1}\right| \leq 1$. It follows that there exists sets of parameters such that for all $M_{t} \in\{0, \ldots, I\}, E\left[\Delta U\left(M_{t-1}, M_{t}\right)\right]>0$. The proposition follows.

Proposition 2: Let the pricing rule and the imitation rule be respectively given by (33) and (31). If, for all $M_{1} \in\{0, \ldots, I\}$ and $M_{2} \in\left\{M_{1}-1, M_{1}, M_{1}+1\right\}, E\left[\Delta U_{n-s}\left(M_{1}, M_{2}\right)\right]>0$ then $\nu$ is an increasing function of $M$ on $\{2, \ldots, I-1\}, \nu(I)>\nu(0)$ and $\nu(I-1)>\nu(1){ }^{7}$

The proposition states that in an economy where noise traders have a larger expected utility than sophisticated investors have, then on average more noise traders participate in the economy than sophisticated investors do.

Lemma: Let $X$ be a random variable with a symmetric support with respect to 0 . If $E(X)>0$ then $\operatorname{Prob}(X>0)>1 / 2$.

Proof: Let $f$ be the density function of $X$ and $D^{+}=\{x \geq 0 \mid$ $f(x)>0\}$.

$$
E(X)=\int_{D^{+}} x[f(x)-f(-x)] d x
$$

${ }^{7}$ Our result does not depend on the technical assumption in the imitation rule. The proposition still holds if we assume that there is always at least one noise trader and one sophisticated investor in the economy. The proposition also holds if we assume that for any $M_{t-1} \in\{1, \ldots, I-1\}$ there is a probability $\alpha$ that a noise trader or a sophisticated investor changes of category independently of the difference in utility observed. This last case is proved in the appendix. 
and

$$
\int_{D^{+}} x[f(x)-f(-x)] d x \leq\left(\int_{D^{+}} x d x\right)\left(\int_{D^{+}}[f(x)-f(-x)] d x\right)
$$

The assumption that $X$ has a symmetric support with respect to 0 , $E(X)>0$ and equation (37) imply that $\operatorname{Prob}(X>0)>1 / 2$. Q.E.D

Proof of Proposition 2: We consider the following Markov process. The state of the economy at time $t$ is represented by $M_{t-1}$ and $M_{t}$. The transition probability from state $\left(M_{t-1}, M_{t}\right)$ to $\left(M_{t}, M_{t}+1\right)$ is given by $\left.P\left(M_{t-1}, M_{t}\right)=\operatorname{Prob}\left(\Delta U_{n-s}\left[M_{t-1}, M_{t}\right)\right]>0\right)$. So given the imitation rule chosen, the transion probability from state $\left(M_{t-1}, M_{t}\right)$ to $\left(M_{t}, M_{t}-1\right)$ is $\left[1-P\left(M_{t-1}, M_{t}\right)\right]$.

Let $\mu(.,$.$) be the equilibrium distribution of this Markov Chain. Then for$ all $M=1, \ldots, I-1$,

$$
\nu(M)=\mu(M, M-1)+\mu(M, M)+\mu(M, M+1)
$$

It should be noted that for all $M \in 2, \ldots, I-2, \mu(M, M)=0$ since those states cannot be reached. We also have

$$
\nu(0)=\mu(0,0)+\mu(0,1)
$$

and

$$
\nu(I)=\mu(I, I)+\mu(I, I-1)
$$

It is immediate that for all $M \in\{2, \ldots, I-2\}$

$$
\begin{aligned}
\mu(M, M-1) & =[1-P(M+1, M)] \mu(M+1, M) \\
& +[1-P(M-1, M)] \mu(M-1, M)
\end{aligned}
$$

and

$$
\mu(M, M+1)=P(M+1, M) \mu(M+1, M)+P(M-1, M) \mu(M-1, M)
$$

Step 1: For all $M \in 2, \ldots, I-2, \mu(M-1, M)=\mu(M, M-1)$.

(i) $\mu(1,2)=\mu(2,1)$.

$$
\mu(0,0)=(1-\alpha) \mu(0,0)+[1-P(1,0)] \mu(1,0)
$$


and

$$
\mu(0,1)=\alpha \mu(0,0)+P(1,0) \mu(1,0)
$$

It follows that

$$
\mu(1,0)=\mu(0,1)=\frac{\alpha}{[1-P(1,0)]} \mu(0,0)
$$

From the imitation rule, $\mu(1,1)=\mu(0,1)$. Furthermore,

$$
\mu(1,0)=[1-P(1,1)] \mu(1,1)+[1-P(2,1)] \mu(2,1)
$$

and

$$
\mu(1,2)=P(1,1) \mu(1,1)+P(2,1) \mu(2,1)
$$

Equations (45), (46), (47) imply that

$$
\mu(1,2)=\mu(2,1)=\frac{\alpha P(1,1)}{[1-P(1,0)][1-P(2,1)]} \mu(0,0)
$$

(ii) Now, if we assume that $\mu(j-1, j)=\mu(j, j-1)$, then (41) and (42) imply that $\mu(j, j+1)=\mu(j+1, j)$

Thus, for all $M=2, \ldots, I-2$

$$
\mu(M-1, M)=\mu(M, M-1)
$$

Step 2: For all $M=2, \ldots, I-2, \nu(M)>\nu(M-1)$. Equations (41), (42) and (49) imply that

$$
\mu(M+1, M)=\frac{P(M-1, M)}{[1-P(M+1, M)]} \mu(M, M-1)
$$

As $E\left(\Delta U_{n-s}\right)$ is always positive by assumption, the lemma above implies that for all $M=2, \ldots, I-2, P(M, M-1)>1 / 2$ and $P(M, M+1)>1 / 2$. Therefore,

$$
\mu(M+1, M)>\mu(M, M-1)
$$


(iii) $\nu(I-1)=\mu(I-1, I)+\mu(I-1, I-1)+\mu(I-1, I-2)$. It follows that

$$
\begin{aligned}
\nu(I- & 1)=\left(\frac{2 P(I-2, I-1)}{[1-P(I-1, I-1)]} \frac{P(1,1)}{[1-P(2,1)]}+\frac{P(1,1)}{[1-P(2,1)]}\right) \\
& \times \frac{P(1,1) P(1,2) \ldots P(I-3, I-2)}{[1-P(1,0)][1-P(3,2)] \ldots[1-P(I-1, I-1)]} \alpha \mu(0,0)
\end{aligned}
$$

As

$$
\nu(1)=\left(2+\frac{P(1,1)}{[1-P(2,1)]}\right) \frac{\alpha}{[1-P(1,0)]} \mu(0,0)
$$

and applying the same argument as in (ii), it follows that $\nu(I-1)>\nu(1)$. Q.E.D.

\section{Some welfare considerations}

As noise traders may survive even when the imitation rule is based on utility levels, we would like to know if the existence of noise traders worsen or improve the welfare of the economy. For this, we modify the assumptions of our model following DSSW (1989).

\subsection{The new assumptions}

The number of noise traders is fixed (i.e. $M_{t}=M$ for all $t$ ) and when young, all traders have the same initial wealth normalized to one. Each share of stock carries ownership of a single unit of physical capital.

The supply of capital is not completely inelastic anymore. The capital is supplied following DSSW (1989) and Pagano (1990). Each period capital can be built from and melted into consumption goods by risk-neutral entrepreneurs. These entrepreneurs can exchange capital for a constant one unit of consumption for each unit of capital good. Entrepreneurs must decide the variation of capital stock in period $t$ during 
Using equation (38), It follows that

$$
\nu(M)-\nu(M-1)=\mu(M, M+1)-\mu(M-2, M-1)>0
$$

Step 3: $\nu(I)>\nu(0)$ and $\nu(I-1)>\nu(1)$.

(i) Proceeding as in step 1, one can show that

$$
\mu(I, I)=\frac{P(I-1, I)}{\alpha} \mu(I-1, I)
$$

and

$$
\mu(I-1, I)=\mu(I-1, I-1)
$$

which is equivalent to

$$
\nu(I)=\frac{P(I-2, I-1)}{[1-P(I-1, I-1)]} \mu(I-2, I-1)
$$

(ii)

$$
\begin{array}{r}
\nu(I)=\mu(I, I)+\mu(I, I-1) \\
\left(1+\frac{P(I-1, I)}{\alpha}\right) \frac{P(I-2, I-1)}{1-P(I-1, I-1)} \mu(I-2, I-1)
\end{array}
$$

Therefore

$$
\begin{array}{r}
\nu(I)=\frac{P(1,1) P(1,2) \ldots P(I-2, I-1)}{[1-P(2,1)][1-P(3,2)] \ldots[1-P(I-1, I-1)]} \mu(0,0) \\
\times\left(\frac{\alpha}{[1-P(1,0)]}\right)
\end{array}
$$

As

$$
\nu(0)=\left(1+\frac{\alpha}{[1-P(1, O)]}\right) \mu(0,0)
$$

and for all $M=1, \ldots,(I-1) P(M, M+1)>1 / 2, P(1,1)>1 / 2$ and $P(I-1, I-1)>1 / 2$, it is immediate that $\nu(I)>\nu(0)$. 
period $t-1$. Then entrepreneurs set the quantity of risky capital available each period at

$$
K_{t}=E_{t-1}\left(N X_{t}+M Y_{t}\right)
$$

This supply rule ensures that the expected value of the stock price $p_{t}$ in the future is always equal to one. Furthermore, we assume that investors are excluded from building capital and entrepreneurs are excluded from trading in stocks.

This model combines two problems studied separately in Pagano (1989) and DSSW (1990), the existence of noise traders and the impact of imperfect competition on traders welfare.

Quantities traded are unchanged. Equating total demand with the stock supply (61) yields

$$
p_{t}=1+\frac{M}{I} \frac{\left(\rho_{t}-\rho^{*}\right)}{(1+r)}
$$

Thus $\operatorname{Var}\left(p_{t+1}\right)$ remains unchanged. Conversely to section 3, here imperfect competition does not influence prices. This is a consequence of the capital supply rule chosen that makes entrepreneurs "adapt" their supply of capital to investors' behaviour.

As imperfect competition reduces quantitites traded by both noise traders and sophisticated investors, the equilibrium capital stock is then reduced compared to a perfectly competitive market. Since the aggregate level of consumption of period $t$ is equal to $I(1+r)+K_{t}\left(\delta_{t}-r\right)$, the smaller the market size, the smaller the level of consumption per individual, on average.

\subsection{The level of social welfare}

We explicitly compute the expected utility of both noise trader and sophisticated investors in order to find out if some government intervention is welcome, and if the answer is yes, which policy should be implemented to increase the level of social welfare.

$$
U_{s}=(1+r)+\frac{I(I-2)}{2(I-1)^{2}}+\frac{\left\{\delta^{*}-r+\frac{M}{I}\left(\rho_{t}-\rho^{*}\right)\right\}^{2}}{\gamma\left\{\sigma_{\delta}^{2}+\frac{M^{2}}{I^{2}} \frac{\sigma_{\rho}^{2}}{(1+r)^{2}}\right\}}
$$


and

$$
U_{n}=(1+r)+\frac{I(I-2)}{2(I-1)^{2}} \frac{\left\{\delta^{*}-r+\left(1-\frac{M}{I}\right) \rho_{t}+\frac{M}{I} \rho^{*}\right\}^{2}}{\gamma\left\{\sigma_{\delta}^{2}+\frac{M^{2}}{I^{2}} \frac{\sigma_{\rho}^{2}}{(1+r)^{2}}\right\}}
$$

It follows that

$$
E_{s}\left(U_{s}\right)=(1+r)+\frac{I(I-2)}{2(I-1)^{2}}\left\{\frac{\left(\delta^{*}-r\right)^{2}+\frac{M^{2}}{I^{2}} \sigma_{\rho}^{2}}{\gamma\left(\sigma_{\delta}^{2}+\frac{M^{2}}{I^{2}} \frac{\sigma_{\rho}^{2}}{(1+r)^{2}}\right)}\right\}
$$

and

$$
E_{n}\left(U_{n}\right)=(1+r)+\frac{I(I-2)}{2(I-1)^{2}} A
$$

where

$$
A=\left\{\frac{\left(\delta^{*}-r\right)^{2}+\rho^{*}\left(\delta^{*}-r\right)+\left(1-2 \frac{M}{I}\right) \rho^{* 2}+\left(\frac{M}{I}-1\right)^{2} \sigma_{\rho}^{2}}{\gamma\left(\sigma_{\delta}^{2}+\frac{M^{2}}{I^{2}} \frac{\sigma_{\rho}^{2}}{(1+r)^{2}}\right)}\right\}
$$

It follows immediately that expected utilities are increasing when the market size increases and when the share of noise traders decreases. Therefore, some government intervention is welcome. Furthermore, one can show that imperfect competition and existence of noise traders do not have additive impact on traders'welfare, i.e. the sum of utility levels obtained by two sophisticated investors trading in an imperfectly competitive economy with noise traders is lower than the sum of utility levels obtained by a sophisticated investor trading in an imperfectly competitive economy in the absence of noise trading and a sophisticated investor trading in a perfectly competitive economy with noise traders.

\subsection{Which kind of government intervention?}

It is easy to see that any kind of policy including taxes is Pareto inferior to open market operations in which the government mimicks sophisticated investors. Any tax policy based on capital gain ${ }^{8}$ in order to reduce noise

\footnotetext{
${ }^{8}$ tax policy proposed in DSSW (1990)
} 
traders' incentive to bet on their misperception would also hurt sophisticated investors and so would reduce the degree of competitiveness. Any taxes-subsidies policy in order to increase market liquidity ${ }^{9}$ would not reduce the share of noise traders in the economy.

Conversely open market operations solve the two problems. In the limit, the market is perfectly competitive and noise traders' share in the economy converges to zero. Expected utility level reached by sophisticated investors is

$$
E\left(U_{s}\right)=(1+r)+\frac{1}{2}\left(\frac{\left(\delta^{*}-r\right)^{2}}{\sigma_{\delta}^{2}}\right)
$$

and expected utility level reached by noise traders is

$$
E\left(U_{n}\right)=(1+r)+\frac{1}{2}\left(\frac{\left(\delta^{*}-r\right)^{2}+\rho^{*}\left(\delta^{*}-r\right)+\rho^{* 2}+\sigma_{\rho}^{2}}{\sigma_{\delta}^{2}}\right)
$$

\section{Conclusion}

Our article has stressed the importance of the degree of competitiveness in the economy when considering market selection processes. Speaking about destabilizing speculation, Friedman (1953) argued that

"Professional investors might on average make money while a changing body of amateurs regularly lost large sums"

If we think of our sophisticated investors as professional investors and noise traders as amateurs, our article can be used to answer Friedman. Amateurs are not expected to make losses but are rather expected to have higher returns than professional investors do. Furthermore, the less competitive the economy, the higher the difference of both return and utility between amateurs and professionals. This result is a consequence of amateurs' market power. By playing non optimal strategies, from a professional investor 's point of view, amateurs hurt professionals more

\footnotetext{
${ }^{9}$ tax policy proposed in Pagano (1989)
} 
than they hurt themselves. Therefore, the difference in welfare level is increased. It follows directly that in such an economy, amateurs may, on average, dominate the market in the long run.

\section{Appendix}

In the case we present now, for any $M_{t-1} \in\{1, \ldots, I-1\}$ there is a probability $2 \alpha$ that no imtation based on $\Delta U\left(M_{t-1}, M_{t}\right)$ occurs. When this happens, there is a probability a half that a noise trader changes himself into a sophisticated investor or that a sophisticated investor changes himself into a noise trader. Thus, for all $M_{t-1} \in\{1, \ldots, I-1\}$ and $M_{t} \in\left\{M_{t-1}, M_{t}, M_{t+1}\right\}$

$$
\begin{gathered}
\operatorname{Prob}\left(M_{t+1}=M_{t}+1\right)=\operatorname{Prob}\left(\Delta U\left(M_{t-1}, M_{t}\right)>0\right)(1-2 \alpha)+\alpha \\
\operatorname{Prob}\left(M_{t+1}=M_{t}-1\right)=\operatorname{Prob}\left(\Delta U\left(M_{t-1}, M_{t}\right)<0\right)(1-2 \alpha)+\alpha \\
\text { If } M_{t-1}=0 \text { and } M_{t}=0 \quad \operatorname{Prob}\left(M_{t+1}=0\right)=1-\alpha \\
\operatorname{Prob}\left(M_{t+1}=1\right)=\alpha \\
\operatorname{Prob}\left(M_{t+1}=0\right)=\alpha \\
\operatorname{Prob}\left(M_{t+1}=1\right)=1-2 \alpha \\
\operatorname{Prob}\left(M_{t+1}=2\right)=\alpha \\
\operatorname{Prob}\left(M_{t+1}=I\right)=1-\alpha \\
\operatorname{Prob}\left(M_{t+1}=I-1\right)=\alpha \\
\operatorname{Prob}\left(M_{t+1}=I\right)=\alpha \\
\text { If } M_{t-1}=I \text { and } M_{t}=1 \quad M_{t-1}=I \text { and } M_{t}=I-1 \quad \\
\quad \operatorname{Prob}\left(M_{t+1}=I-1\right)=1-2 \alpha \\
\operatorname{Prob}\left(M_{t+1}=I-2\right)=\alpha
\end{gathered}
$$


Proposition 3: Let the pricing rule and the imitation rule be respectively given by (33) and (i). If, for all $M_{1} \in\{0, \ldots, I\}$ and $M_{2} \in$ $\left\{M_{1}-1, M_{1}, M_{1}+1\right\}, E\left[\Delta U_{n-s}\left(M_{1}, M_{2}\right)\right]>0$ then $\nu$ is an increasing function of $M$ on $\{2, \ldots, I-1\}, \nu(I)>\nu(0)$ and $\nu(I-1)>\nu(1)$.

Proof: Equations (38), (39) and (40) still hold and for all $M \in$ $\{2, \ldots, I-1\}$ we have

$$
\begin{gathered}
\mu(M-1, M)=[P(M-2, M-1)(1-2 \alpha)+\alpha] \mu(M-2, M-1) \quad(\mathrm{ii}) \\
+[P(M, M-1)(1-2 \alpha)+\alpha] \mu(M, M-1) \\
\mu(M-1, M-2)=[\{1-P(M-2, M-1)\}(1-2 \alpha)] \mu(M-2, M-1)(\mathrm{iii}) \\
+\alpha \mu(M-2, M-1) \\
+[\{1-P(M, M-1)\}(1-2 \alpha)+\alpha] \mu(M, M-1)
\end{gathered}
$$

We deduce that for all $M \in\{2, \ldots, I-1\}$

$$
\mu(M-1, M)+\mu(M-1, M-2)==\mu(M-2, M-1)+\mu(M, M-1)
$$

Step 1: For all $M \in\{1, \ldots, I\}, \mu(M-1, M)=\mu(M, M-1)$

(i) $\mu(0,1)=\mu(1,0)$

Given the imitation rule,

$$
\begin{array}{r}
\mu(0,0)=[\{1-P(1,0)\}(1-2 \alpha)+\alpha] \mu(1,0) \\
+(1-\alpha) \mu(0,0)
\end{array}
$$

and,

$$
\mu(0,1)=\alpha \mu(0,0)+[P(1,0)(1-2 \alpha)+\alpha] \mu(1,0)
$$

It follows that

$$
\mu(0,1)=\mu(1,0)=\frac{\alpha \mu(0,0)}{[\{1-P(1,0)\}(1-2 \alpha)+\alpha]}
$$


(ii) $\mu(1,2)=\mu(2,1)$

Given the imitation rule,

$$
\begin{gathered}
\mu(1,1)=(1-2 \alpha) \mu(0,1) \\
\mu(1,0)=[\{1-P(2,1)\}(1-2 \alpha)+\alpha] \mu(2,1) \\
+[\{1-P(1,1)\}(1-2 \alpha)+\alpha] \mu(1,1)+\alpha \mu(0,1) \\
\mu(1,2)=[P(2,1)(1-2 \alpha)+\alpha] \mu(2,1) \\
+[P(1,1)(1-2 \alpha)+\alpha] \mu(1,1)+\alpha \mu(0,1)
\end{gathered}
$$

Equations (viii) and (ix) imply

$$
\mu(2,1)=A_{1} \mu(0,1)
$$

where

$$
A_{1}=\frac{2 \alpha(1-\alpha)+(1-2 \alpha)^{2} P(1,1)}{\{1-P(2,1)\}(1-2 \alpha)+\alpha}
$$

(ix) and (x) imply

$$
\mu(1,0)+\mu(1,2)=2 \alpha \mu(0,1)+\mu(1,1)+\mu(2,1)
$$

Putting (viii), (xi) and (xii) into (xiii), we deduce that $\mu(1,2)=A_{1} \mu(1,0)$ and so $\mu(1,2)=\mu(2,1)$.

(iii) For all $M \in\{1, \ldots, I-2\}, \mu(M, M+1)=\mu(M+1, M)$ Given that $\mu(1,2)=\mu(2,1)$ and using equation (iv), the result is immediate.

$$
\text { (iv) } \mu(I-1, I)=\mu(I, I-1)
$$

We proceed as in (ii).

$$
\begin{array}{r}
\mu(I-1, I-1)=(1-2 \alpha) \mu(I, I-1) \\
\mu(I-1, I)=[P(I-2, I-1)(1-2 \alpha)+\alpha] \mu(I-2, I-1) \\
+\alpha \mu(I, I-1) \\
+[P(I-1, I-1)(1-2 \alpha)+\alpha] \mu(I-1, I-1)
\end{array}
$$




$$
\begin{array}{r}
\mu(I-1, I-2)=[\{1-P(I-2, I-1)\}(1-2 \alpha)+\alpha] \mu(I-2, I-1)(\mathrm{xvi}) \\
+\alpha \mu(I, I-1) \\
+[\{1-P(I-1, I-1)\}(1-2 \alpha)+\alpha] \mu(I-1, I-1)
\end{array}
$$

(xv) and (xvi) imply that $(1-2 \alpha) \mu(I-1, I)=\mu(I-1, I-1)$, thus

$$
\mu(I, I-1)=\mu(I-1, I) .
$$

Step 2: For all $M \in\{2, \ldots, I-1\}$

$$
\mu(M, M-1)=\frac{P(M-1, M-2)(1-2 \alpha)+\alpha}{[1-P(M, M-1)](1-2 \alpha)+\alpha} \mu(M-1, M-2) \quad(\text { xviii })
$$

Using equations (ii) and (iii) and step1, the result is immediate.

Step 3: For all $M \in\{2, \ldots, I-2\}, \nu(M+1)>\nu(M)$.

Using step 2 and lemma 1 , the result is immediate.

Step 4: $\nu(I)>\nu(0)$ and $\nu(I-1)>\nu(1)$

Equations (xv), (xvi) and (xvii) imply that $\mu(I-1, I)=A_{2} \mu(I-2, I-1)$ where

$$
A_{2}=\frac{P(I-1, I-2)(1-2 \alpha)+\alpha}{2 \alpha(1-\alpha)+(1-2 \alpha)^{2}[1-P(I-1, I-1)]}
$$

The imitation rule imply that $\alpha \mu(I, I)=[\alpha+P(I-1 . I)(1-$ $2 \alpha)] \mu(I-1, I)$

Given that for all $M_{1} \in\{2, \ldots, I-1\}$ and $M_{2} \in\left\{M_{1}-1, M_{1}, M_{1}+1\right\}$. $P\left(M_{1}, M_{2}\right)>1 / 2$, it follows that $A_{2}^{-1}<A_{1}$. Proceeding as in the proof of proposition 2, we have the desired result. Q.E.D.

\section{References}

[1] Alchian A. (1950): "Uncertainty, evolution and economic behavior". Journal of Political Economy, 58: 211-221. 
[2] Black F. (1971): "Towards a fully automated exchange, part I", Financial analysts Journal, 27: 29-34.

[3] Blume L. and Easley D. (1989): "Wealth dynamics and the market selection hypothesis", Working paper, Cornell University.

[4] Conlisk J. (1980): "Costly optimizers against cheap imitators", Journal of Economic Behavior and Organization, 1: 275-293.

[5] De Long B., Shleifer A., Summers L. and Waldmann R. (1989): "The size and incidences of losses from noise trading", Journal of Finance, 44: 681-696.

[6] De Long B., Shleifer A., Summers L. and Waldmann R. (1990): ' Noise trader risk in financial markets", Journal of Political Economy, 98: 703-738.

[7] De Long B., Shleifer A., Summers L. and Waldmann R. (1991): " The survival of noise traders in financial markets", Journal of Business, 64: 1-18.

[8] Enke S. (1951):" On maximizing profits: a distinction between chamberlin and Robinson", American Economic Review, 41: 566-578.

[9] Friedman M. (1953): "the case of flexible exchange rates", in Essays in positive economics, the University of Chicago Press: 157-203.

[10] Kyle A. (1984): "A theory of futures market manipulations", in "the industrial organization of futures markets", R.W. Anderson Ed.: 141-191.

[11] Kyle A. (1985): "Continuous auction and insider trading", Econometrica, 53: 1315-1335.

[12] Kyle A. (1989): "Informed speculation with imperfect competition", Review of Economic Studies, 56: 317-356.

[13] Lakonishok J., Shleifer A. and Vishny R. (1991): "Do institutional investors destabilize stock prices? evidence on herding and feedback trading", NBER Working paper No. 3846.

[14] Pagano M. (1989): "Endogeneous market thiness and stock price volatility", Review of Economic Studies, 56: 269-288. 
[15] Schaffer M (1989): "Are profit-maximizer the best survivors?", Journal of Economic Behavior and Organization, 12: 29-45. 



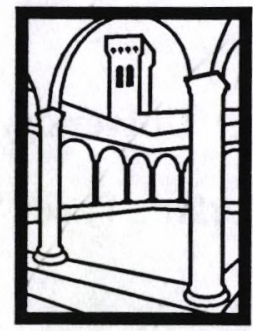

EUI

WORKING

PAPERS

EUI Working Papers are published and distributed by the European University Institute, Florence

Copies can be obtained free of charge

- depending on the availability of stocks - from:

The Publications Officer

European University Institute

Badia Fiesolana

I-50016 San Domenico di Fiesole (FI)

Italy 


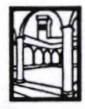

\section{Publications of the European University Institute}

\section{Economics Department Working Paper Series}

To
Department of Economics WP
European University Institute
Badia Fiesolana
I-50016 San Domenico di Fiesole (FI)
Italy

From

Name

Address.

(Please print)

$\square$ Please enter/confirm my name on EUI Economics Dept. Mailing List

$\square$ Please send me a complete list of EUI Working Papers

$\square$ Please send me a complete list of EUI book publications

$\square$ Please send me the EUI brochure Academic Year 1994/95

Please send me the following EUI ECO Working Paper(s):

No, Author

Title:

No, Author

Title:

No, Author

Title:

No, Author

Title:

Date 


\section{Working Papers of the Department of Economics Published since 1993}

ECO No. 93/1

Carlo GRILLENZONI

Forecasting Unstable and Non-Stationary Time Series

ECO No. 93/2

Carlo GRILLENZONI

Multilinear Models for Nonlinear Time Series

ECO No. 93/3

Ronald M. HARSTAD/Louis PHLIPS

Futures Market Contracting When You Don't Know Who the Optimists Are

ECO No. 93/4

Alan KIRMAN/Louis PHLIPS

Empirical Studies of Product Markets

ECO No. 93/5

Grayham E. MIZON

Empirical Analysis of Time Series:

Illustrations with Simulated Data

ECO No. 93/6

Tilman EHRBECK

Optimally Combining Individual

Forecasts From Panel Data

ECO NO. 93/7

Víctor GÓMEZ/Agustín MARAVALL Initializing the Kalman Filter with Incompletely Specified Initial Conditions

ECO No. 93/8

Frederic PALOMINO

Informed Speculation: Small Markets

Against Large Markets

ECO NO. 93/9

Stephen MARTIN

Beyond Prices Versus Quantities

ECO No. 93/10

José María LABEAGA/Angel LÓPEZ

A Flexible Demand System and VAT

Simulations from Spanish Microdata

ECO No. 93/11

Maozu LU/Grayham E. MIZON

The Encompassing Principle and

Specification Tests
ECO No. 93/12

Louis PHLIPS/Peter MØLLGAARD

Oil Stocks as a Squeeze Preventing

Mechanism: Is Self-Regulation Possible?

ECO No. 93/13

Pieter HASEKAMP

Disinflation Policy and Credibility: The

Role of Conventions

ECO No. 93/14

Louis PHLIPS

Price Leadership and Conscious

Parallelism: A Survey

ECO No. 93/15

Agustín MARAVALL

Short-Term Analysis of Macroeconomic Time Series

ECO No. 93/16

Philip Hans FRANSES/Niels

HALDRUP

The Effects of Additive Outliers on Tests for Unit Roots and Cointegration

ECO No. 93/17

Fabio CANOVA/Jane MARRINAN

Predicting Excess Returns in Financial Markets

ECO No. 93/18

Iñigo HERGUERA

Exchange Rate Fluctuations, Market

Structure and the Pass-through

Relationship

ECO No. 93/19

Agustín MARAVALL

Use and Misuse of Unobserved

Components in Economic Forecasting

ECO No. 93/20

Torben HOLVAD/Jens Leth

HOUGAARD

Measuring Technical Input Efficiency for

Similar Production Units:

A Survey of the Non-Parametric

Approach 
ECO No. 93/21

Stephen MARTIN/Louis PHLIPS

Product Differentiation, Market Structure and Exchange Rate Passthrough

ECO No 93/22

F. CANOVA/M. FINN/A. R. PAGAN

Evaluating a Real Business Cycle Model

ECO No 93/23

Fabio CANOVA

Statistical Inference in Calibrated Models

ECO No 93/24

Gilles TEYSSIÈRE

Matching Processes in the Labour Market in Marseilles. An Econometric Study

ECO No 93/25

Fabio CANOVA

Sources and Propagation of International

Business Cycles: Common Shocks or

Transmission?

ECO No. 93/26

Marco BECHT/Carlos RAMÍREZ

Financial Capitalism in Pre-World War I

Germany: The Role of the Universal

Banks in the Financing of German

Mining Companies 1906-1912

ECO No. 93/27

Isabelle MARET

Two Parametric Models of Demand,

Structure of Market Demand from

Heterogeneity

ECO No. 93/28

Stephen MARTIN

Vertical Product Differentiation, Intra-

industry Trade, and Infant Industry

Protection

ECO No. 93/29

J. Humberto LOPEZ

Testing for Unit Roots with the k-th

Autocorrelation Coefficient

ECO No. 93/30

Paola VALBONESI

Modelling Interactions Between State and Private Sector in a "Previously" Centrally Planned Economy
ECO No. 93/31

Enrique ALBEROLA ILA/J. Humberto

LOPEZ/Vicente ORTS RIOS

An Application of the Kalman Filter to the Spanish Experience in a Target Zone (1989-92)

ECO No. 93/32

Fabio CANOVA/Morten O. RAVN

International Consumption Risk Sharing

ECO No. 93/33

Morten Overgaard RAVN

International Business Cycles: How

much can Standard Theory Account for?

ECO No. 93/34

Agustín MARAVALL

Unobserved Components in Economic

Time Series

ECO No. 93/35

Sheila MARNIE/John

MICKLEWRIGHT

"Poverty in Pre-Reform Uzbekistan:

What do Official Data Really Reveal?"

ECO No. 93/36

Torben HOLVAD/Jens Leth

HOUGAARD

Measuring Technical Input Efficiency for

Similar Production Units:

80 Danish Hospitals

ECO No. 93/37

Grayham E. MIZON

A Simple Message for Autocorrelation

Correctors: DON'T

ECO No. 93/38

Barbara BOEHNLEIN

The Impact of Product Differentiation on Collusive Equilibria and Multimarket Contact

ECO No. 93/39

H. Peter MØLLGAARD

Bargaining and Efficiency in a

Speculative Forward Market

潘洸 
ECO No. 94/1

Robert WALDMANN

Cooperatives With Privately Optimal

Price Indexed Debt Increase Membership

When Demand Increases

ECO No. 94/2

Tilman EHRBECK/Robert

WALDMANN

Can Forecasters' Motives Explain

Rejection of the Rational Expectations

Hypothesis?

ECO No. 94/3

Alessandra PELLONI

Public Policy in a Two Sector Model of

Endogenous Growth

ECO No. 94/4

David F. HENDRY

On the Interactions of Unit Roots and

Exogeneity

\section{ECO No. 94/5}

Bernadette GOVAERTS/David F. HENDRY/Jean-François RICHARD

Encompassing in Stationary Linear

Dynamic Models

ECO No. 94/6

Luigi ERMINL/Dongkoo CHANG

Testing the Joint Hypothesis of Rationality and Neutrality under Seasonal Cointegration: The Case of Korea

ECO No. 94/7

Gabriele FIORENTINI/Agustín

MARAVALL

Unobserved Components in ARCH

Models: An Application to Seasonal

Adjustment

ECO No. 94/8

Niels HALDRUP/Mark SALMON

Polynomially Cointegrated Systems and their Representations: A Synthesis

ECO No. 94/9

Mariusz TAMBORSKI

Currency Option Pricing with Stochastic Interest Rates and Transaction Costs:

A Theoretical Model

ECO No. 94/10

Mariusz TAMBORSKI

Are Standard Deviations Implied in

Currency Option Prices Good Predictors of Future Exchange Rate Volatility?
ECO No. 94/11

John MICKLEWRIGHT/Gyula NAGY

How Does the Hungarian Unemployment Insurance System Really Work?

ECO No. 94/12

Frank CRITCHLEY/Paul

MARRIOTT/Mark SALMON

An Elementary Account of Amari's

Expected Geometry

ECO No. 94/13

Domenico Junior MARCHETTI

Procyclical Productivity, Externalities and Labor Hoarding: A Reexamination of Evidence from U.S. Manufacturing

ECO No. 94/14

Giovanni NERO

A Structural Model of Intra-European

Airline Competition

ECO No. 94/15

Stephen MARTIN

Oligopoly Limit Pricing: Strategic

Substitutes, Strategic Complements

ECO No. 94/16

Ed HOPKINS

Learning and Evolution in a

Heterogeneous Population

ECO No. 94/17

Berthold HERRENDORF

Seigniorage, Optimal Taxation, and Time

Consistency: A Review

ECO No. 94/18

Frederic PALOMINO

Noise Trading in Small Markets 


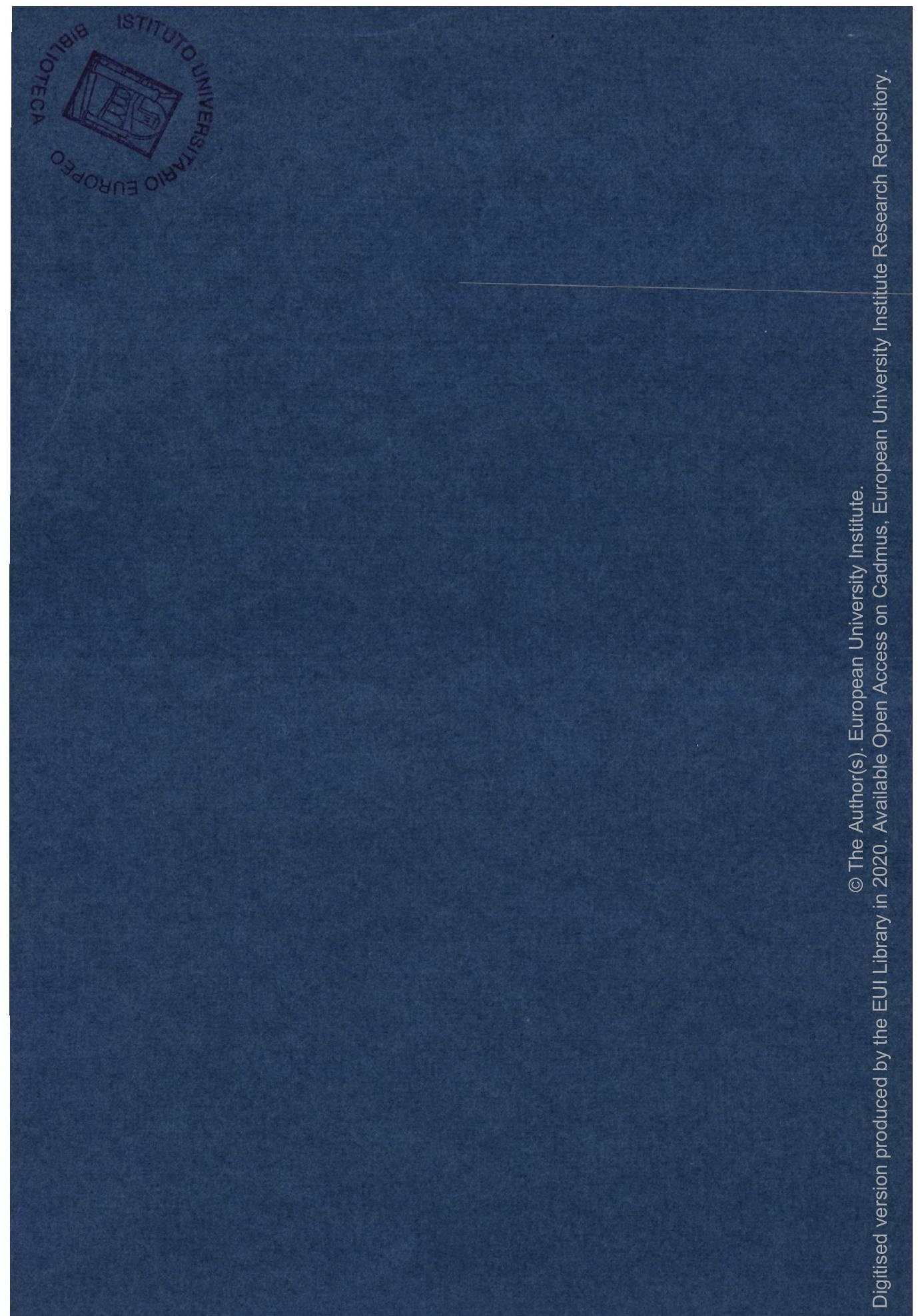

